\title{
The Role of the Private Sector in Global Climate and Energy Governance
}

\author{
José Célio Silveira Andrade $\cdot$ José Antônio Puppim de Oliveira
}

Received: 15 January 2014/ Accepted: 21 May 2014/Published online: 7 June 2014

(C) Springer Science+Business Media Dordrecht 2014

\begin{abstract}
The private sector plays an active role in implementation of mechanisms concerning the mitigation of climate change. In spite of that, the corporate actors play a limited direct role in international arenas when it comes to negotiating the design of climate and energy regime. The climate and energy governance in the United Nations system remains mostly state-centric, but the active participation of corporate actors in negotiation of climate and energy regimes is essential to increase the effectiveness of their governance. Business is not just a subject of a regulatory climate and energy imposed by the state; rather, business is an intrinsic part of the fabric of climate and energy governance, as "rule-maker," particularly in the many voluntary regimes. However, the architecture in place should guarantee that the private sector does not highjack the decisions and its positions are balanced by other non-governmental actors in the process. This article analyzes the role that the private sector can play in the global climate and energy governance. The private sector does not only play a "rule taker" role in the climate change and energy regime. Indeed, they are not passive observers as they influence through indirect means. The results suggest that the private sector is able to play a key role in global climate and energy governance based on the principle of multi-stakeholder participation in global decisionmaking, but the architecture should be able to balance the
\end{abstract}

J. C. S. Andrade ( $\bowtie)$

Management School, Federal University of Bahia, Salvador, Bahia, Brazil

e-mail: jcelio.andrade@gmail.com

J. A. Puppim de Oliveira

United Nations University - Institute of Advanced Studies

(UNU-IAS), Tokyo, Japan

e-mail: puppim@ias.unu.edu goods and bads of private direct influence in international regimes.

Keywords Architecture - Climate change - Energy · Governance · Private sector

\section{Introduction}

The global climate and energy governance has been discussed by diplomats, scientists, and other stakeholders since the Conference of Rio in 1992, without major progress in the capacity of the international community to reduce the total emissions of Greenhouse Gases (GHG). We thus face a paradoxical situation, even though there is a growing institutional, human, financial, and scientific resources devoted to the global climate and energy governance system, GHG emission rate continues to increase in a dangerous scale (IPCC 2007, 2013). There are several factors that explain the failure in the process of getting the emissions down: (a) the lack of implementation and effectiveness of the global climate and energy governance regimes; (b) a decision-making process insufficiently open to the participation of other sectors, such as industry, forests, trade, health, finances, or development, which are key for reducing emissions; (c) lack of policy implementation at the national and sub-national levels of government; and (d) a state-centric system that does not allow the effective inclusion of multiple international actors including the private sector (Andrade and Taravella 2009).

This state-centric system leaves out the major role that the private sector can play and ignores the contemporary context marked by an increasing complexity of the global governance process. The global climate and energy governance remains based on nation-state-oriented designs and 
processes of international relations (IR) established in the last century. Recent major environmental conferences, such as the Copenhagen Climate Change Conference (UNFCCC COP 15) and Rio +20 , all failed to produce internationally binding agreements with clear targets and goals to tackle climate change. Environmental institutions need to recognize that sovereign states no longer tackle challenges alone; globalization requires strong cooperation among nationstates and non-state actors, such as private companies and private environmental standards organizations, environmental groups, and indigenous people, as well as subnational governments such as municipalities and provinces. A key feature of such post-sovereign governance is the emergence of what amounts to a division of labor among governments and non-governmental actors involved in environmental governance that comprises global green pluralism. In that light, a strong consensus on the need to reform the global climate and energy governance system, in particular, and the global environmental governance system, in general, has emerged (Kanie et al. 2013).

Any global climate and energy governance reform should also account for the role that corporate actors play in international environmental politics. This challenge also applies to the theoretical frameworks used to conceptualize, analyze, and understand global climate and energy governance (Okereke and Bulkeley 2007). IR as a discipline have largely neglected the role of corporate actors in making global public policy. The dominance of the state-centric regulation paradigm has meant that the influence of business as political actors has been little explored in the study of international politics (O’Neill 2009). Similarly, little attention has so far been paid to the role of corporations as political actors in global climate and energy governance by the specific business ethics and Corporate Social Responsibility (CSR) literatures (Rasche et al. 2008; Eberlein and Matten 2009).

As a result, the global climate and energy governance and the conceptual frameworks of global environmental politics have accorded only marginal attention to business actors. However, in practice, the business world is increasingly engaged in international environmental politics. Even though they were seen as opponents to any environmental regulation in the 1970s and climate change "deniers" in the 1990s, businesses have become more active in 2000s as "global partners" in international environmental politics through the development of private and hybrid (public-private) governance regimes. In spite of this encouraging evolution, the private sector is still confined mainly to the role of "ruletaker" in the global climate and energy governance system.

\footnotetext{
1 Throughout this paper, the term "rule-taker" will be used to refer to an actor who follows, sometimes against his own will, a set of rules established by other actors. A "rule-maker," by contrast, chooses to take part directly in the construction of the rules of the game.
}

There is thus a real hiatus between the conceptualization of global climate and energy governance and its actual dynamics. The private sector plays an active role in implementation of mechanisms concerning the mitigation of climate change, including the Kyoto Protocol (Campbell 1998). Nevertheless, the corporate actors play a limited direct role in international arenas when it comes to negotiating the design of climate and energy regime. The climate and energy governance in the United Nations system remain state-centric, but the active participation of corporate actors in negotiation of climate and energy regimes is essential to increase the efficiency of the climate and energy governance. Business is not just a subject of a regulatory climate and energy imposed by the state; rather, business is an intrinsic part of the fabric of climate and energy governance as a de facto "rule maker," once business actors remain active in the backstage lobbies and negotiations, as well as influential in national and subnational regimes.

This hiatus poses a three-fold problem. First, it prevents us from fully comprehending the evolution of the role of companies from "rule-takers" to "rule-makers." Second, it limits the way we could foster the innovative role of the private sector as "rule-maker" to make the regimes more effective to deliver the changes. Third, it is very difficult to learn from this phenomenon in order to strengthen the place of the private sector in the global climate and energy governance in order to make the governance more transparent and just.

In order to make contributions to reduce the conceptual gap on the role of business in global climate and energy governance, this article focuses on the analysis of the ways in which the corporate actors respond to the agenda of global climate and energy governance and how they could play a key role in the changing architecture of global climate and energy governance, as well as the possible changes to make this participation more positive and effective.

This paper is divided into three parts. We will first review the expansion of the participation of the private actors in the global climate and energy governance and describe their evolution as "rule-takers" and the emergence of their new role as "rule-makers." Second, we will examine the contribution of business actors to the effectiveness of the global climate and energy governance, analyzing the potential, limits, and constraints of strengthening the role of the private sector in global climate and energy governance system. By analyzing the place that the global climate and energy governance system grant to the private sector and showing the shortcomings of this system in harnessing the potential role of private actors, the third section of this paper will discuss the type of architecture governance system in order to have a balanced contribution of these actors. 
The concluding section suggests that there are ways business actors can play a more positive role as "rulemakers" and this should be considered in any reforms of the global climate and energy governance that aims to make regimes more effective. However, the architecture in place should guarantee that the corporations and the private sector do not highjack the decisions. Its positions should be balanced by other non-governmental actors in the process, such as: (a) international governmental organizations (IGOs); (b) NGOs, indigenous and other activist groups, global environmental movements; (c) scientific community, experts groups, and knowledge holders; (d) the broader public and individual leaders.

\section{The Growing Engagement of the Business Actors in the Global Climate and Energy Governance}

\section{The Evolution as "Rule-Taker"}

Historically, business actors positioned themselves in opposition to any national and international environmental policies and regulations, seen as true threats to their competitiveness. The additional and constraining environmental regulations were generally considered additional production costs. To quell the adoption of these regulations, the business actors first privileged forms of indirect action, taking advantage of their influence among national decision makers/parliamentarians to oppose or weaken new global environmental regimes or their implementation at the national or local levels. This political action rests on an intense lobbying activity. It was the dominant political strategy used by the private sector at the United Nations Conference on the Human Environment in Stockholm back in 1972 (Porter and Brown 1996).

The Earth Summit in Rio in 1992 marked the beginning of a change in corporate environmental strategy for some business actors. Rio witnessed an increasing and more direct participation of the private sector in international environmental conferences. This change was aimed at better representing business interests in the international arena. Maurice Strong, organizer of the Rio Summit, and former business leader, played a key role in welcoming two private sector groups in global environmental governance: the World Business Council for Sustainable Development (WBSCD) and the International Chamber of Commerce (ICC). Thus, using an interpretation of sustainable development centered on the reconciliation of economic and socio-environmental interests, the WBCSD and the ICC lobbied governmental delegations directly in Rio de Janeiro. Their objective was simple: to promote the idea of a partnership among the private sector, environmentalists and the international community in finding common solutions to global environmental problems, and argue that business and environmental interests were compatible through the idea of eco-efficiency (Schmidheiny 1992). In particular, their political strategy sought support for certain specific types of governance mechanisms, such as marketoriented and industry-based self-regulation instruments. On the basis of these two guiding principles, the two business institutions produced a voluntary environmental code of conduct: the ICC Business Charter for Sustainable Development. This industry-based standard opened the doors in the 1990s to the growth of private environmental regimes in the global climate and energy governance. While interest in private environmental governance has grown recently, the active involvement of corporate actors in shaping private environmental regimes is not entirely new. For example, the US Chemical Manufacturers Association, together with its Canadian counterpart, developed the Responsible Care program in the 1980s to promote environmental and safety principles and management codes within the global chemical industry (Falkner 2003; GarciaJohnson 2000; Clapp and Thistlethwaite 2012).

\section{The Initiatives of "Rule-Maker"}

Private and hybrid governance regimes have become an important component of the global climate change institutional architecture, particularly due to the failure of achieving intergovernmental binding agreements. Private partnership systems of governance often complement multilateral environmental regimes by filling regulatory or governance gaps when intergovernmental cooperation fails. The most outstanding characteristic of private partnerships is the non-state-centric nature of the arrangement (Kanie et al. 2013). They clearly indicate the capacity and the ability of business actors, organized in transnational networks, to create their own environmental regimes, which in turn affect the overall structures of the global climate and energy governance. Business initiatives have stimulated the debate about the role of the corporate actors in the multilevel global environmental governance and influenced the structure of the global climate and energy governance through the inclusion of market-oriented and industry-based self-regulation instruments. These are seen, by private actors, as the only environmental regulation mechanisms able to respond to the shortcomings of traditional command-and-control state-based regulations (Knox-Hayes and Levy 2011; Kollmuss et al. 2008; Clapp 2005).

Eberlein and Matten (2009) argue that traditional command-and-control state-based regulation and business ethics have a mutually exclusive relation: business ethics addresses areas where regulation either does not exist or is insufficiently enforced. Addressing sweatshop working 
conditions or voluntary initiatives for GHG reduction are cases in point. Companies such as Ford or General Motors, in the absence of governmental regulation on climate change, have developed policies and practices with regard to an ethical response to this issue. The regulatory environment also shapes businesses' ethical approaches. When comparing climate change policies and the role of business in Canada and Germany, the dichotomy between business ethics and regulation is still rather distinct: while Germany is a highly regulated environment for climate change, Eberlein and Matten (2009) see less voluntary initiatives by business; however, the largely absent regulatory framework in Canada seems to leave space for a number of ethically motivated initiatives by industries, business groups, and individual businesses.

Thus, transnational corporate actors influence the global climate and energy governance through their participation as "rule-makers" in other global and national environmental regimes, such as through the development of voluntary initiatives, which later can become legitimate standards and shape broader regimes. The proliferation of private and hybrid environmental regimes, such as carbon offset standards of the voluntary carbon market (Voluntary Carbon Standard-VCS, Gold Standard, VER+, The Voluntary Offset Standard-VOS, Chicago Climate Exchange-CCX, The Climate, Community and Biodiversity Standards-CCBS, ISO 14064, ISO 5001, WRI/ WBCSD GHG Protocol for Project Accounting) and voluntary global climate change reporting system (e.g., Carbon Disclosure Project-CDP), is a clear example of the growing role of the private sector as "rule-maker" in the global climate and energy governance. These forms of environmental self-regulation are frequently carried out by business groups and carbon market actors in partnership with non-governmental organizations (NGOs) and backed by cities and national governments and International Organizations (IOs). Prior research suggests that voluntary corporate climate change disclosure mechanisms contribute to enhance the firm's environmental legitimacy (Peters and Romi 2013). The corporate image of the largest companies is closely linked to their performance in the field of CSR and the disclosure of information on a specific aspect of CSR, the environment, and more concretely, one aspect of it, climate change (Prado-Lorenzo and GarciaSanchez 2010).

The CDP standards, for example, while initially designed as a voluntary set of standards, are now recognized as legitimate standards by some governments and IOs. The CDP was initiated by a group of $22 \mathrm{UK}$ institutional investors in 2000. Now, CDP comprises a group of 534 global institutional investors who are responsible for managing US\$ 57 trillion and who plan to invest in socially responsible companies that hold similar corporate values (CDP 2013).
Nowadays, several countries and cities, particularly in North America, Latin America, Asia, and Europe, have supported CDP. The CDP has received funding from various national governments around the world, including the governments of Australia, Canada, France, Germany, Singapore, Spain, Sweden, Denmark, UK, and USA. CDP is also supported by various local governments around the world, including Toronto, New York City, and London. The IOs, including the EU, OECD, and numerous UN bodies on global climate change and energy, have recognized the CDP standards as a legitimate investor (banks, pension funds, asset managers, insurance industry and foundations)-led initiative to accelerate company action on cost-effective carbon reduction activities (CDP 2013).

Thus, although there are a variety of more established general environmental principles and codes of conduct in the financial sector, such as the Principle for Responsible Investment (PRI) and Equator Principles, other specific climate-related voluntary programs emerged recently beyond the CDP. The Climate Risk Action Plan, the Climate Principles, and the Carbon Principles are examples of programs that banks and other investors can use to evaluate and reduce the impact of their investments have on climate change. They set guidelines for the financial and investment industries (Clapp and Thistlethwaite 2012). These initiatives are multi-stakeholders governance regimes, including the Investor Network on Climate Risk, banks like Citibank, JP Morgan Chase, Morgan Stanley, and several large US power companies and environmental NGOs.

Before presenting the main reasons for this change from "rule-takers" to "rule-makers," we highlight that businesses are not homogeneous in their interests and actions. Indeed, starting in the 1990s, the change has been observed in only the more progressive segments of the private sector. A few companies decided to replace their traditionally defensive and critical posture with a more proactive strategy that sought to deliver innovative responses to the challenges posed by global environmental regimes. This change stemmed from for four main reasons: (1) the emergence of a "green and low carbon economy" which considers the climate and energy regulations as an opportunity for growth and profit; (2) the progressive awakening by some companies of the risk which global climate change problems could represent to their legitimacy and competiveness; (3) the perception that a strong, effective and efficient global climate and energy governance is central to the development of the business world since it guarantees a clear and stable institutional environment; (4) the incentives given by IGOs and States for a more active role of private actors in finding solutions to global climate change issues (Le Prestre 2005).

The increasing involvement of the private sector in global environmental governance has increased beyond 
Rio-92. The arrival of Kofi Annan as UN Secretary-General marked a new stage in the history of the industry's involvement in global environmental governance. In the end of 1990s, he began to seek close cooperation with business and industry as an integral part of the UN reform. Private actors were perceived as part of the solution rather than as a problem to regulate. Thus, business groups were officially invited as observers as well as to contribute to debates at global conferences which have served to shape the environmental agenda of the UN. This new "observer" status allowed them to be present during the discussions, to make statements at the beginning of negotiation sessions, to distribute informative documents outside the plenary, to have a formal voice on advisory technical committees and other forms of influence on negotiation processes (Ivanova et al. 2007; Bled 2007).

Annan was also key to propose the creation of the UN Global Compact during the World Economic Forum of Davos in January 1999. It is a voluntary initiative target mainly on the business sector worldwide with two main objectives: Mainstreaming social and environmental issues defined in the ten general principles in business activities and bringing businesses to support UN goals and actions. The Global Compact is based largely on five international documents: The Universal Declaration of Human Rights, The International Labour Organization's Declaration on Fundamental Principles and Rights at Work, The Rio Declaration on Environment and Development, and The United Nations Convention against Corruption, but implementation is voluntary. With over 7,000 business participants and other stakeholders from more than 145 countries, the UN Global Compact perhaps is the most prominent example of a voluntary set of principles at the international level. The specific environmental goals include adoption of the precautionary principle, the promotion of environmental responsibility, and the development and diffusion of cleaner technologies, all issues that have a bearing on global climate change and energy governance (Clapp and Thistlethwaite 2012; UN Global Compact 2014).

There have been several criticisms of the Global Compact (Ruggie 2002). The fact that it is voluntary makes difficult to get a hold in the more problematic companies, which in general do not participate in those initiatives. The lack of accountability is another limitation. Reports are generally made by companies. There is little monitoring of the reports, particularly the veracity of the actions. Indeed, some studies demonstrate that very few companies report properly, and most of the reports look like promotion material and less like a detailed report. For example, Sethi and Schepers (2013) show that the UN Global Compact has failed to induce its signatory companies to enhance their CSR efforts and integrate the 10 principles in their policies and operations. The result has been a loss of public trust and support of UN Global Compact from important constituencies among civil society organizations, and those individuals and groups adversely impacted by corporate activities and resultant negative externalities. Finally, the use of the UN (blue) symbol is viewed as a "Blue-Wash" mechanism to serve more to blue marketing for companies and promote themselves than to promote the principles (Bruno 2002). However, the criticisms have been debated. The introduction of compulsory mechanisms to monitor companies would take a long time to be agreed upon, if ever, as well as to get the support for the Global Compact from key UN members. And ultimately, any global "command-and-control" kind of regulation would be completely opposed by most of the businesses.

Thus, in practice, global governance mechanisms are often limited in terms of the actors they involve, the levels they address and their network-based steering mode. To strengthen the relation between the global governance system and the UN Global Compact initiative to make the former more effective would require the initiative's institutional design and accountability to reflect the multilevel, multiactor, and network-based steering mode that global governance system ideally calls for (Rasche and Gilbert 2012).

With the evolution of business as rule-makers, advocacy groups such as the WBCSD and the ICC have increased the visibility and influence of business in international forums. These groups, so-called businesses and industry NGOs (BINGOs), play a prominent role in multilateral environmental negotiations for several reasons. Initially, BINGO membership is the means by which companies gain physical access to the multilateral negotiations. In order to attend and participate in international negotiations, a company must be member of a BINGO accredited by the multilateral environmental agreement (MEA) Secretariats. In addition to physical access, the BINGO also provides various logistical services to their member companies during the negotiations, such as, information exchange and networking, sites for the negotiation of "position papers," organization of side events and information booths. A second more important function of BINGOs is to negotiate a consensus among their member organizations and projects a united front in international environmental forums. Finally, the third role of BINGOs in multilateral environmental negotiations is to channel the input of their members into the political process. This important function facilitates the implementation of various private-sector political strategies in the negotiations process, such as preparation of newsletters, position papers and reports, co-operation with national delegations and conventional lobbying activity through formal and informal channels (Pulver 2005).

In fact, Levy and Newell (2005) underline that an examination of a firm as a global political actor needs to 
extend beyond traditional political strategy, such as lobbying and financial donations for election campaigns. In the negotiation of many international regimes, business actors have a formal voice on advisory technical panels and in the process of production and revision of scientific reports. These actors also play a role of knowledge-broker, providing technological and economic information in the form of technical papers and constructing what is and is not policy-relevant knowledge, as well as funding scientific projects. When analyzing multinational corporations' political strategy on climate change, Kolk and Pinkse (2007) show that their type of political activities can be characterized as information strategies to influence policy makers toward market-based solutions, rather than withholding action on emission reduction.

Moreover, business uses a range of political strategies to influence directly or indirectly the formation, maintenance, and disintegration of global environmental regimes. They are indeed recognized for using their technological knowhow and expertise in innovation to find solutions to specific climate change and energy problems, such as the substitution of fossil fuels for renewable ones, and for directly influencing the global climate change regime through participation in some of the country official delegations. Influence can also be indirect through the structural power of large corporations in the economy or the implicit threat of relocation (Levy and Newell 2005). This refers to the ability of multinational corporations to influence the formation and functioning of governance through their dominant position in the global economy, which allows them to shape mainstream ideology and state-policy formation. Clapp and Dauvergne (2005) stress that in the current era of increasing global economic competition, many States pursue domestic policy outcomes acceptable to corporations in order to keep or attract investment for their countries. In other words, the indirect influence that private actors have on the formation of broader ideological norms and discourses may in fact lead the State to open more direct channels of influence over governance.

Begun in the 1990s, the transition of the private sector from the role of "rule-taker" to that of "rule-maker," continued in the following decade. It appeared forcefully during the 2002 UN Conference on Sustainable Development in Johannesburg, where discussions about global environmental governance system reform focused on two aspects: international institutional architecture and the role of the various international actors (States, IGOs, NGOs, private sector, etc.). The UN Corporate Accountability Convention at this conference sparked the debate about the appropriate role of firms at global environmental summits, and the need for a strong participation of corporate actors in order to increase the efficiency and effectiveness of global environmental regimes.
The UN Under Secretary-General Nitin Desai welcomed ex-Shell Chairman Mark Moody-Stuart as head of BASD (Business Action for Sustainable Development). The BASD, a coalition of business groups designed in 2001 by WBCSD and ICC to be the main corporate voice for the Johannesburg, played a large role in the Summit, claiming that industry was part of the solution rather than a threat to the environment and a problem to regulate (Bruno 2002). Corporate actors again played a key role in promoting voluntary self-regulation and market-oriented initiatives, rather than direct regulation of corporations. They tried to keep the focus on voluntary corporate responsibility that includes environmental awareness, their preferred way of addressing environmental issues (Clapp and Dauvergne 2005).

Indeed, Johannesburg proposed to improve cooperation with the corporate sector, through a new type of governance built on "public-private partnerships" designed to translate global environmental principles into local sustainable development projects. It stressed that the inclusion and the active involvement of legitimate corporate actors in the global environmental governance system were key to the implementation of international environmental regimes and essential to increasing the effectiveness of MEAs. This kind of hybrid regimes of governance has generated controversy. Some authors see those regimes as part of a broader process of privatization of the UN system, where private actors are increasingly carrying out the work of the UN while benefiting from the neutral humanitarian reputation of the organization (Bruno 2002).

\section{The Potential Contribution and Limits of Business Actors to the Effectiveness of the Global Climate and Energy Governance}

Corporations are now considered critical players in solving global environmental problems as they exert an impact both on the environment and on environmental governance (Morgera 2006). An active cooperation of corporate actors as "rule-makers" can be key to the effectiveness of the global climate and energy governance. Rather than analyzing the "problem" of business actors, this section examines the "potential, limits and constraints" for the private sector to strengthen global climate and energy governance and work toward sustainable development.

The Potential for Business Actors to Improve the Effectiveness of the Global Climate and Energy Governance

Why is strengthening private sector's role an acceptable first step toward effective global climate and energy governance? Essentially because, private sector could 
contribute to addressing some dimensions of ineffectiveness of the global climate and energy governance. The first dimension is lack of capacity for MEAs implementation. Businesses can help with resources and expertise in the implementation of mechanisms concerning the mitigation and adaptation of climate change as we have seen when there are economic incentives to participate in and comply with global climate agreements, such as the Clean Development Mechanism (CDM) of the Kyoto Protocol. A second dimension of ineffectiveness lies in a global climate and energy governance decision-making process insufficiently opened to the input of others sectors. Decisions affecting global climate and energy governance taken place outside the MEA arena, in areas such industry, forests, trade, investment and international development, where business actors have played a growing role as "rule-makers," must be coherent with policies resulting from MEAs. For the governance system as a whole to be effective, it needs to find ways to mainstream climate change considerations into economic decisions and to ensure meaningful coherence between climate change and other global policy spheres. For example, some relevant WTO rules must be discussed with a view to establishing their coherence with global climate change and energy regimes (Sampson 1998). A third dimension of ineffectiveness stems from the inability of the state-centric UN system to allow for the more active and direct participation of business actors in all phases of policy-making, generating "parallel" competing regimes without strong input of other stakeholders, weakening official regimes. The private sector is becoming increasingly engaged as a "rule-maker" in the global climate and energy governance through private regimes and public-private partnerships, such as the Carbon Disclosure Project (CDP) and Voluntary Carbon Markets (Kollmuss et al. 2008).

In sum, four major elements suggest the potential positive role businesses can have to help the global climate and energy governance become more effective. Firstly, business controls key resources-financial, technological and organizational - that play a critical role in determining the effectiveness of international environmental regimes. Their central role in directing investments and the pace of innovation is bound to give them a prominent position in international environmental politics (Falkner 2007).

Secondly, business should take part in all phases of treaty negotiations that will affect them directly, because this can likely ensure greater compliance later on (Clapp and Dauvergne 2005). The active participation of stakeholders in the global climate and energy governance process tend to lead to more effective regulation and higher compliance, thus helping to increase the implementation rate of agreements (Streck 2004). If a global climate agreement cannot be crafted with the consent of major affected industries, there will likely be no agreement at all, or a weak pledge. Indeed, no climate regime can likely succeed politically without support of major corporate players (Newell 2000), as they are influential in many country delegations. In short, more political participation is believed to lead to more effective problem solving and support of the decisions (Bäckstrand 2006). However, as business can sometimes exercise the veto-coalition role through indirect means, the relationship between a more positive participation and effectiveness depends on the values, power and interest of those who are participating to make sure they represent the broad interest of the private sector and not solely their narrow individual business interests.

Thirdly, business participation and cooperation are central to the implementation and functioning of regimes, as for example the Kyoto Protocol's flexibility mechanisms. Companies are central actors in the governance of the global carbon economy (emissions trading and joint implementation) and played a key role in the creation of the CDM. It has the explicit objective to both reducing GHG emissions and supporting sustainable development in developing countries. Businesses played an important role in the power generation sector of developing countries and emerging economies by providing additional revenue to support the diffusion of renewable energy sources. Indeed, companies took on many different roles in the CDM project cycle. Businesses with potential to participate in the CDM include not only project developers and investors but companies engaged in activities as diverse as technology development and transfer, contract negotiation, brokerage and trading (Streck 2004; Karakosta et al. 2012, 2013; Gangale and Mengoline 2011). In practice, the CDM relies heavily on the private sector, with non-state actors both implementing and supervising projects (Kulovesi 2007). Several private initiatives have been established to create carbon-trading systems among participating companies, such as the World Bank's Prototype Carbon Fund (PCF), which was established in 2000 as a public-private partnership between a few national governments, including the Netherlands, Sweden, Japan, and Canada, and 26 companies, including Hydro-Québec, Daimler-Chrysler, ShellCanada, BP-Amoco, and numerous Japanese firms (Levy and Jones 2008; Kollmuss et al. 2008).

Despite the voluntary carbon markets represents only a small fragment $(2,2 \%)$ in the total global emissions trading, the participation of companies in those voluntary initiatives increased at almost double the rate of regulated markets in the 2000s, such as the European Union's Emissions Trading Scheme (EU ETS), or the CDM. Until recently there were at least two different types of voluntary markets in operation, one of them now defunct (Clapp and Thistlethwaite 2012). The voluntary GHG emissions cap- 
and-trade schemes, the Chicago Climate Exchange (CCX), opened in October 2003 with 22 members, including American Electric Power, DuPont Motorola and Ford. From October 2003 through July 2010 CCX operated as a cap-and-trade program with an offsets component. In 2011 CCX launched the Chicago Climate Exchange Offsets Registry Program to register Verified Emission Reductions (VER) based on a set of established protocols (ICE 2013). Another voluntary market outside the CCX, the "over-thecounter" (OTC) market, operates on a deal-by-deal basis where companies purchase "GHG offsets" for the emissions. Over $65 \%$ of trades in the voluntary carbon market occur through the OTC market (Clapp and Thistlethwaite 2012).

Thus, the effectiveness of the climate change treaty seems closely linked to the results of private sector involvement. The active role for private actors in the regulated and voluntary carbon markets could be seen as a new ingredient in the climate regime to increase its effectiveness. Nevertheless, the nation-states are important for successful global climate and energy governance, particularly in terms of creating proper national regulations and networking of actors (Brühl 2002; Kanie et al. 2013).

Fourthly, concrete, result-driven collaborations with business can, in turn, lead to a strengthened global climate and energy governance system through: (1) effective partnership that deliver results at the local level; (2) improved economic and technical expertise within the global climate and energy governance system when business is engaged as a knowledge-broker; (3) an increased authority for the global climate and energy governance system as a result of wide participation and effectiveness. Partnership with business is said to bring technology, investment, or organizational and managerial skills. The involvement of business in the system promises to offer new supply networks, new monetary resources, and new sources of legitimacy to United Nations Framework Convention on Climate Change-UNFCCC (Ivanova et al. 2007).

\section{Limitations of the Role of Business Actors as Elements of a Stronger Global Climate and Energy Governance}

It is clear from the literature that there is no consensus on whether business involvement is a bane or a boon to global environmental governance and more particularly to the global climate and energy governance (Andrade and Taravella 2009). Many questions that have been raised regarding the role of the private sector in the global climate and energy governance concern its legitimacy and effectiveness. From a critical perspective, an increasing and more direct participation of the private sector actors in the global climate and energy governance decision-making can be problematic because of their lack of legitimacy, since their participation is not the product of elections or have any political legitimacy. Neither are NGOs, but it is easier for the latter to claim that they represent the public interest, whereas companies are mainly driven by profit and possess substantial economic resources that they can use to enhance their political position (Brühl 2002). In addition, an expanded influence of corporate actors in the global climate and energy governance might trigger a shift away from international environmental regulations to favor economic goals (Clapp and Dauvergne 2005).

Private regimes of governance can also generate ethical dilemmas as they can have negative effects on income distribution and justice (Kalfagianni 2013). For example, a private regime of governance can alleviate some global environmental problems (e.g., reduction of GHG emissions with the use of biofuels), but can create or intensify global inequalities (e.g., biofuel production can threaten food security). In case of trade-offs, we need to know which aspects need to be strengthened and where appropriate interventions are desirable from a business ethics perspective.

The accountability shown in the hybrid regimes of governance may also pose more problems of legitimacy. As Bäckstrand (2006) emphasized, how can these global governance structures be accountable if the actors themselves are not politically accountable? However, as she also argued, it is problematic to use criteria stemming from an ideal-type national democracy in order to evaluate the legitimacy and accountability of, for example, transnational public-private networks, in an environment devoid of a supranational authority. Because of the broad range of actors involved, accountability mechanisms need to be pluralistic and the traditional hierarchical accountability mechanisms may have to be replaced with non-hierarchical ones. The voluntary offset market in particular has been criticized for its lack of transparency. For example, several groups had in the past criticized CCX for its general lack of transparency. By 2007, when yet operated as a cap-andtrade program, CCX responded to this criticism by making its rule book and many of the methodologies available on its website (Kollmuss et al. 2008).

Representation in private regimes of governance may equally pose problems of legitimacy. For example, Clapp (2005) argues that the private regimes of governance represent a privatization of global environmental governance. The legitimacy of the corporate actors to establish global norms for climate change is questioned, especially if the standard setting process is dominated by the energy industry, with only minor inputs from governments and environmental NGOs. Moreover, the weak commitment of the broader corporate world represents another obstacle to a legitimated participation of the private sector in the global environmental regimes. Although the increasing engagement of business actors in the global climate and energy 
governance is a contemporary tendency, the vast majority of companies remains unengaged and absent from the main international climate change forums (Ivanova et al. 2007). They tend to overestimate the adaptation costs to new environmental rules and to underestimate opportunity costs, which encourages a defensive and passive "rule-taker" strategy in the international environmental regulation process. It is clear that some firms and sectors are far more engaged in the global politics of decision making on climate change issues than others. Larger Western multinational firms are more closely involved in crafting environmental policies as they are well-organized politically and better represented in global forums than smaller firms and companies from poor countries. The example of the climate change regime is very representative of this situation. Three large multinational companies (Dupont, BP and Shell) assumed a leading role in shaping global climate policies by developing a more proactive "rule-maker" strategy. They sought competitive advantages by contributing to shaping the rules of the game, as institutional entrepreneurs, whereas many other companies, thinking the climate issue too complex, found it easier to adopt a defensive or waitand-see "rule-taker" attitude (Dunn 2005).

Thus, private climate change standards could serve as trade or entry barriers and have potentially negative implications for developing countries that do not have as much representation as industrialized countries in organizations such as the WBCSD or the ICC. Equally, the decision-making process around the private regimes of governance is dominated by concerns of the better represented multinational companies that attend the bodies' meetings, rather than those of the far more numerous, but less mobilized, small and medium enterprises. Levy and Newell (2005) argue that one of the commercial drivers of private forms of self-regulation is the desire to keep smaller firms out of profitable markets by raising the barrier to entry and increasing the costs of compliance with standards. As a result, though a positive relationship between corporate environmental performance and the level of voluntary climate change disclosure could be expected (Dawkins and Fraas 2011), private, hybrid private-public or "mixed" regimes of governance are perhaps more significant as a barrier against competition from smaller companies, than as a framework for improving environmental performance.

\section{Major Constraints for an Effective Participation}

of Private Sector in the Global Climate and Energy Regimes

If the weak commitment of the broader corporate world represents one of the obstacles to a stronger participation of the private sector in the global environmental governance, how could business become more engaged in the process of developing climate change and energy regimes? If it is quite clear that a direct participation of the private sector as "rule-maker" is very important for the effectiveness of the global climate and energy governance system, what are the main constraints that prevent business actors from realizing their full potential?

Major constraints can be found outside and within the business world for an effective participation of private sector in the global climate and energy regimes. The literature mentions four main obstacles, as discussed below:

(1) Firstly, as stressed by Kolk and Hoffmann (2007), the complexities, uncertainties, and fragmentation of current global climate change and energy policy seem to be major factors that impede more pro-active business responses.

(2) Secondly, another important obstacle resides in the current conflicts within the business world's responses to the agenda of global climate change and energy politics. The business world is not a monolithic entity and different business groups disagree on what should be private sector's roles and responses to climate change. Not all business actors are engaged in international politics; not all of those that are share the same interest; and not all of those that seek to influence international politics succeed or do it in a positive way. Business conflict arises in the global climate change and energy politics because of the different effects that international regulatory measures may pose on individual companies and industries.

According to Falkner (2007), at least three forms of business inter-sector or/and intra-sector conflicts can be identified with regard to international regulation, norm setting, and regime building such as the global climate change and energy governance. The first form of conflict is related to a basic dividing line that exists between private multinationals and government controlled firms. For example, large traditional private oil firms like Shell and $\mathrm{BP}$, are actively involved in climate change discussions and rule setting, but government controlled firms, such as China's Sinopec are less active. A second form of business conflict can arise between technological leaders and laggards in the same industry or economic sector. In this case, the dividing line is found between competitors in a given market segment that are likely to experience different effects of regulation due to their uneven ability to comply with new standards. As Pinkse and Kolk (2009) highlighted, in some cases, climate change and energy regulation can lead to new commercially viable products, and technological leaders can therefore use regulatory politics to create new business models and achieve competitive advantage. For example, Brazil's oil company Petrobras is keen to promote first-generation biofuels for mitigating climate change as Brazil has some leading technologies and geographical advantages for biofuel production. The 
third and another source of business conflict are the differences in lobbying styles. For example, American and European firms differ significantly in the way they lobby. Levy and Newell (2000) and Levy and Kolk (2002) have noted the more adversarial style of business lobbying in the United States as opposed to Europe where the approach is more toward dialog and corridor lobbying. This reflects broader differences in corporate strategy and institutional settings. Firms in the United States have been able to contest the scientific rationales for environmental action more openly and directly, while in Europe such positions are generally less acceptable (Levy and Newell 2005).

In sum, business conflicts are an important feature of business involvement in global climate change and energy politics and result from an absence of consensus regarding the best strategic response to influence multilateral environmental negotiations. Thus, these conflicts weaken the capacity of the private sector to speak with a unified voice and to argue for a specific policy direction when engaging in environmental politics. For example, the conflicts of interests and the trans-Atlantic differences in lobbying styles within the Global Climate Coalition (GCC) led this BINGO to lose members (diverging members went on to create the Pew Center on Global Climate Change as an alternative to the GCC in 1998), and GCC finally withdrew from the international climate change arena in 2002 (Ivanova et al. 2007; Dunn 2005; Bled 2007). The clash of political styles was central to the downfall of the United States-based GCC. Beyond policy disagreements over appropriate action to be adopted in the face of climate change, BP and Shell rejected the GCC's aggressive lobbying tactics and the negative press they generated. Pulver (2005) attributes the failure of the GCC to export an American model of politics to the international arena, which alienated its European members. An American-style model refers to adversarial politics where regulation is the product of interest groups activities, and business wields influence through the action of lobbying groups in Washington D.C. In contrast, the European model relies on a more consultative process based on a clear division of responsibilities. Government sets the regulatory agenda and turns to relevant interest groups for advice.

(3) Thirdly, "anti-politics" function of the BINGOs represents another crucial obstacle to the ability of business to migrate from the role of "rule-taker" to that of "rulemaker" in global climate change and energy governance (Pulver 2005). Many companies state that their role can only be 'a-political' in global climate change and energy governance, but the conduct of some companies has been far from neutral. Also, companies cannot be neutral; the very fact that a company conducts activities within a political environment, such as the climate change negotiations or economic regulations at the national level, makes it a political actor (Rasche et al. 2008). And, can a company really stay 'neutral' or 'a-political' in the context of discussions about future energy regulations? Companies that have easy access to governments tend to wield political influence out of the public eye. For these companies it is more rational to play a political role outside the public forums and project a non-political identity inside the official negotiation arenas or to the media. They can easily remove themselves from direct intervention in the political process and prefer not to appear as political actors in the international and national consultations, leaving this role to BINGOs. Clapp and Dauvergne (2005) highlight that companies make fewer public interventions than environmental NGOs (for example, in plenary sessions and smaller meetings), but they are active in the corridors, lobbying and shaping the positions of states, as well as even ending up on national delegations.

Thus, BINGOs can play an "anti-politics" role in establishing distance between their member companies and the political process. However, in the context of the international environmental negotiations, the "anti-politics" function imposed on BINGOs has become a major obstacle to the development of the private sector as "rulemaker." It exacerbates conflicts among the member companies and makes it difficult for BINGOs to organize consensus and project a united front in environmental debates (Pulver 2005).

(4) Fourthly, one of the toughest obstacles to the participation of the private sector as "rule-maker" resides in the institutional architecture of the UN global environmental governance system. Although the UN has begun incorporating business actors into the global environmental governance system through access to policy-making forums and partnerships, the current state-centric nature of global environmental governance in the decisions does not offer sufficient room for business actors to express their full potential. The global environmental governance system locks up the business actors in the role of implementing MEAs and offers them only a marginal institutional place to directly design global environmental regimes. The current state-centric model of the global environmental governance system does not let corporate actors take a central and transparent place in shaping the rules of the game directly, and in turn making businesses more accountable to the public, what leave them to play the role of influencing the process for whatever means are available, such as lobbying and blocking implementation at the national level. It expresses a traditional separation between "rulemakers" (the state actors) and "rule-takers" (the non-state actors) that needs to be changed in order to grant the private sector a stronger role as an "engine" of global climate change and energy policy-making. This active participation of legitimate corporate actors as "rule-makers" in 
negotiating international environmental regimes is essential to strengthening the global climate change and energy governance system (Najam et al. 2006).

The change in the representation system is fundamental because the current situation induces a dangerous perverse effect that has to be resisted. Attending multilateral negotiations as observers and not as political decision-makers, corporate actors do not have to clarify to the public their policy positions and their contribution to the effectiveness of global climate change and energy governance. Then, the limited institutional space for observers that is accorded business actors by the UN global environmental governance system seems much more comfortable to some of them as opposed to the status of political decision-makers. Indeed, the "rule-maker" role entails taking real responsibility regarding their own ethical views and position in the solution of global climate change.

\section{Architecture to Balance the Contribution of Business in Climate Discussions}

Effectiveness of multilateral agreements is linked to the negotiation processes, but how these links would evolve with more direct business participation to shape both negotiation and implementation are still unclear. Business actors affected by the agreement can shape the negotiation outcomes to their own self-interest, but they can also provide valuable information to the negotiation process. Moreover, they could be more willing to cooperate in implementation if they participate in the decision process. The challenge is to find a balance in the architecture between the benefits of business participation and the risks to the public good that this participation may involve.

The architecture should take into consideration how to smooth the power and influence of big businesses if they are included. There are some models already in place for quite a long time, such as the negotiation model of the International Labor Organization (ILO). ILO brings together governments, employees and employers in a tri-partite discussion to develop its initiatives. The power and interests of the employers are counter-balanced by employees (e.g., representatives of labor unions). The agreements reached have been discussed by all interested parts, which will also help in legitimizing the implementation.

For international environmental agreements, the inclusion of business directly in the negotiation would have to come with the inclusion of counter-forces such as environmental groups. The later could restrain business from having a disproportional weight in the negotiations. There are some experiences like this in national and sub-national commissions on environmental policy in Brazil (Puppim de Oliveira 2005).
The representation of businesses in the discussions should also be an important point in the architecture. Who would represent whom? The UN has had experience with the stakeholders or major groups discussions during the different UN meetings, such as UNFCCC COPs. Relying in representatives of international BINGOs, such as WBCSD, has been a common practice. However, if direct participation is allowed, probably new groups would claim themselves as representatives. Thus, establishing a set of criteria to represent businesses in the discussions should be defined clearly.

New architecture should also include businesses beyond the large multinationals, as those generally participate in the meetings because they have the resources and expertise to be present and influential. Actors in networks at the international level not always have the same values, power and interests as the networks of the same actors at the national or local level. For example, the companies that participate in the international negotiations are generally large MNCs, but often Small and Medium Enterprises (SMEs) are more important to have an effective implementation at the local level in many cases. Those actors are often unaware of the international discussions and implementation efforts and lack the capacity to make the necessary changes to address the issues. Local actors have different priorities for policy actions than the objectives of many international agreements and their implementation (Pinto and Puppim de Oliveira 2008). Particularly in the environmental area the mismatch can be huge. For example, local governments, businesses and population in the many parts of the Amazon depend on the timber industry and agriculture to collect economic benefits from the forested land in the short-term. Climate change has a much larger and diffuse impact, but the locals are just marginally benefiting on those in the long term. The need to balance the local interest in the global agenda is key to get support for implementation at the local level.

The flip side for having business participation is that there is a need to increase their accountability in the architecture. Businesses are not keen in having international direct regulation as a way to solve the problems, and prefer voluntary or market-based mechanisms. However, regimes with voluntary implementation, such as the UN Global Compact, are criticized because of lack of accountability. Businesses do not lose much when they do not implement their commitments. Thus, representation of business should imply making them more accountable for the decisions made and agreed. Even though the level of accountability in the commitments at the UN is low, as no country is penalized for not ratifying or implementing an agreement, the creation of more rigid enforcement and accountability for businesses participating in the negotiations would make business more committed to the decisions and negotiations. On the other hand, larger accountability could scare some 
business groups from the negotiations. Thus, the architecture should increase accountability without creating barrier for participation of less progressive businesses, which often are the most problematic.

\section{Conclusion}

Companies know better than almost anyone else how and what can and cannot be done in their own production processes to achieve certain environmental outcomes. They can also be powerful actors in the international and national policy arenas to shape international agreements and national legislation for their own interest, besides lobbying and financing studies that show evidences backing their own position. In the case of the ozone depleting substances (ODS) control, CFC producing companies, which were skeptical in the beginning, became very active in responding to legislators and trying to deny the relation between CFCs and the ozone hole. They were also active in trying to influence the discussions in the Montreal Protocol. However, when science was clear, they started to cooperate and became active in influencing the implementation to phase out the CFCs (Benedick 1998).

Companies can also influence agreements to make them weaker, so implementation will not regulate their business directly. Businesses are actively participating in shaping international regimes and their implementation depends on business' interests in moving the agenda ahead, and generally they lobby heavily against any form of regulation. A heavier business regulation at the international level would be difficult to get approval from the business communities or the parties, and its enforcement as a hard law would be prohibitively expensive. Thus, businesses can be an influential force to shape both negotiations and implementation. Business inputs in negotiation process should be mediated to have the right balance between getting the right information for shaping the negotiations to have more effective implementation and avoiding the process of being captured by business interests. Therefore, the challenges are to find ways to include the valuable information and resources businesses have for making any international environmental regime effective and avoid that their interests influence negatively the outcomes of the regime.

\section{References}

Andrade, J. C. S., \& Taravella, R. (2009). Les oubliés de la réforme de la gouvernance internationale de l'environnement. Critique Internationale, 45(1), 119-139.

Bäckstrand, K. (2006). Multi-stakeholder partnerships for sustainable development: Rethinking legitimacy, accountability and effectiveness. European Environment, 16(1), 290-306.
Benedick, R. E. (1998). Ozone diplomacy. New directions in safeguarding the planet. CambridgeUSA: Harvard University Press.

Bled, A. (2007). Global environmental politics: Regulation for or against the private sector? The case of the Cartagena Protocol on biosafety. Political Perspectives, 1(5), 20-42.

Brühl, T. (2002). The privatisation of international climate governance. In F. Biermann, R. Brohm \& K. Dingwerth (Eds.) Proceedings of the 2001 Berlin conference on the human dimensions of global environmental change "Global environmental change and the nation state” (pp. 371-380). Potsdam: Potsdam Institute for Climate Impact Research.

Bruno, K. (2002). Greenwash +10: The UN's Global Compact, Corporate Accountability and the Johannesburg Earth Summit. California: CorpWatch.

Campbell, L. (1998). Emission trading, joint implementation and the clean development mechanism: The role of private sector and the other non-state actors in implementation. In W. B. Chambers (Ed.), Global climate governance: Inter-linkages between the Kyoto Protocol and other multilateral regimes (pp. 15-30). Tokyo: UNU/IAS.

CDP. (2013). Members \& Signatories. http://www.cdproject.net/enUS/Pages/HomePage.aspx. Accessed October 27, 2013.

Clapp, J. (2005). Global environmental governance for corporate responsibility and accountability. Global Environmental Politics, 5(3), 23-34.

Clapp, J., \& Dauvergne, P. (2005). Paths to a Green World: The political economy of the global environment. Cambridge, Mass.: MIT Press.

Clapp, J., \& Thistlethwaite, J. (2012). Private voluntary programs in environmental governance: Climate change and the financial sector. In K. Ronit (Ed.), Business and climate policy: The potentials and pitfalls of private voluntary programs (pp. 53-74). New York: United Nations University Press.

Dawkins and Fraas. (2011). Coming clean: The impact of environmental performance and visibility on corporate climate change disclosure. Journal of Business Ethics, 100(2), 303-322.

Dunn, S. (2005). Down to business on climate change: An overview of corporate strategies. In K. Begg, F. Woerd, \& D. L. Levy (Eds.), The business of climate change: Corporate responses to Kyoto (pp. 31-46). Sheffield: Greenleaf.

Eberlein, B., \& Matten, D. (2009). Business responses to climate change regulation in Canada and Germany: Lessons for MNCs from emerging economies. Journal of Business Ethics, 86(2), 241-255.

Falkner, R. (2003). Private environmental governance and international relations: Exploring the links. Global Environmental Politics, 3(2), 72-87.

Falkner, R. (2007). Business power and conflict in international environmental politics. Basingstoke: Palgrave Macmillan.

Gangale, F., \& Mengoline, A. (2011). CDM contribution to RES penetration in the power generation sector of China and India. International Journal of Sustainable Development and World Ecology, 18(4), 283-290.

Garcia-Johnson, R. (2000). Exporting environmentalism: US multinational chemical corporations in Brazil and Mexico. Cambridge, MA: MIT Press.

ICE (2013). Chicago Climate Exchange. http://www.theice.com/ccx. jhtml. Accessed October 31, 2013.

IPCC. (2007). Climate change 2007: Synthesis report. In Core Writing Team, R. K. Pachauri \& A. Reisinger (Eds.), Contribution of working groups I, II and III to the fourth assessment report of the intergovernmental panel on climate change. Geneva: IPCC.

IPCC. (2013). Summary for policymakers. In T. F. Stocker, D. Qin, G.-K. Plattner, M. Tignor, S. K. Allen, J. Boschung, A. Nauels, 
Y. Xia, V. Bex \& P. M. Midgley (Eds.), Climate change 2013: The physical science basis. Contribution of working group I to the fifth assessment report of the intergovernmental panel on climate change. Cambridge: Cambridge University Press.

Ivanova, M., Gordon, D., \& Roy, J. (2007). Towards institutional symbiosis: Business and the United Nations in environmental governance. RECIEL, 16(2), 123-134.

Kalfagianni, A. (2013). Addressing the global sustainability challenge: The potential and pitfalls of private governance from the perspective of human capabilities. Journal of Business Ethics,. doi:10.1007/s10551-013-1747-6.

Kanie, N., et al. (2013). Green pluralism: Lessons for improved environmental governance in the 21st century. Environment: Science and Policy for Sustainable Development, 55(5), 14-30. doi:10.1080/00139157.2013.824339.

Karakosta, C., Doukas, H., \& Psarras, J. (2012). Carbon market and technology transfer: Statistical analysis for exploring implications. International Journal of Sustainable Development and World Ecology, 19(4), 311-320.

Karakosta, C., Marinakis, V., Letsou, P., \& Psarras, J. (2013). Does the CDM offer sustainable development benefits or not? International Journal of Sustainable Development and World Ecology, 20(1), 1-8.

Knox-Hayes, J., \& Levy, D. (2011). The politics of carbon disclosure as climate governance. Strategic Organization, 9(1), 91-99.

Kolk, A., \& Hoffmann, V. (2007). Business, climate change and emissions trading: Taking stock and looking ahead. European Management Journal, 25(6), 411-414.

Kolk, A., \& Pinkse, J. (2007). Multinationals' political activities on climate change. Business and Society, 46(2), 201-228.

Kollmuss, A., Zink, H., \& Polycap, C. (2008). Making sense of the voluntary carbon market: A comparison of carbon offset standards. Germany: WWF.

Kulovesi, K. (2007). The private sector and the implementation of the Kyoto Protocol: Experiences, challenges and prospects. RECIEL, 16(2), 145-157.

Le Prestre, P. (2005). Protection de l'environnement et relations internationales: les défis de l'écopolitique mondiale. Paris: Armand Colin.

Levy, D. L., \& Jones, C. A. (2008). Business strategies and climate change, United States. http://www.eoearth.org/article/Business_ strategies_and_climate_change,_United_States. Accessed September 21, 2009.

Levy, D. L., \& Kolk, A. (2002). Strategic responses to global climate change: Conflicting pressures on multinationals in the oil industry. Business and Politics, 4(3), 275-300.

Levy, D. L., \& Newell, P. J. (2000). Oceans apart? Business responses to global environmental issues in Europe and the United States. Environment, 42(9), 8-20.

Levy, D. L., \& Newell, P. J. (Eds.). (2005). The business of global environmental governance. Cambridge, Mass.: MIT Press.

Morgera, E. (2006). The UN and corporate environmental responsibility: Between international regulation and partnerships. RECIEL, 15(1), 93-109.

Najam, A., Papa, M., \& Taiyab, N. (2006). Global environmental governance: A reform agenda. Winnipeg, Manitoba: IDDRI.
Newell, P. (2000). Climate change: Non-state actors and the politics of the greenhouse. Cambridge: Cambridge University Press.

O'Neill, K. (2009). The environment and international relations. UK: Cambridge University Press.

Okereke, C., \& Bulkeley, H. (2007). Conceptualizing climate change governance beyond the international regime: A review of four theoretical approaches. Tyndall Centre Working Paper 112.

Peters, G. F., \& Romi, A. M. (2013). Does the voluntary adoption of corporate governance mechanisms improve environmental risk disclosures? Evidence from greenhouse gas emission accounting. Journal of Business Ethics. http://ssrn.com/abstract=2163074. Accessed April 04, 2013.

Pinkse, J., \& Kolk, A. (2009). International business and global climate change. London: Routledge.

Pinto, R., \& Puppim de Oliveira, J. (2008). Implementation challenges in protecting the global environmental commons: The case of climate change policies in Brazil. Public Administration and Development, 28(5), 340-350.

Porter, G., \& Brown, J. W. (1996). Global environmental politics (2nd ed.). Boulder, Colorado: Westview Press.

Prado-Lorenzo, J.-M., \& Garcia-Sanchez, I.-M. (2010). The role of the board of directors in disseminating relevant information on greenhouse gases. Journal of Business Ethics, 97(3), 391-424.

Pulver, S. (2005). Organising business: Industry NGOs in the climate debates. In K. Begg, F. Woerd, \& D. L. Levy (Eds.), The business of climate change: Corporate responses to Kyoto (pp. 47-60). Sheffield: Greenleaf.

Puppim de Oliveira, J. (2005). Enforcing protected area guidelines in Brazil: What explains participation in the implementation process? Journal of Planning Education and Research - JPER, 24(4), 420-436.

Rasche, A., Baur, D., Huijstee, M., Ladek, S., Naidu, J., Perla, C., et al. (2008). Corporations as political actors-A report on the first swiss master class in corporate social. Responsibility Journal of Business Ethics, 80(2), 151-173.

Rasche, A., \& Gilbert, D. U. (2012). Institutionalizing global governance: The role of the United Nations global compact. Business Ethics: A European Review, 21(1), 100-114.

Ruggie, J. G. (2002). The theory and practice of learning networks: Corporate social responsibility and the global compact. Journal of Corporate Citizenship, 5(1), 27-36.

Sampson, G. (1998). WTO rules and climate change: The need for policy coherence. In W. B. Chambers (Ed.), Global climate governance: Inter-linkages between the Kyoto Protocol and other multilateral regimes (pp. 12-25). Tokyo: UNU/IAS.

Schmidheiny, S. (1992). Changing course: A global business perspective on development and the environment. Cambridge, MA: The MIT Press.

Sethi, S. P., \& Schepers, D. H. (2013). United Nations global compact: The promise-performance gap. Journal of Business Ethics,. doi:10.1007/s10551-013-1629-y.

Streck, C. (2004). New partnerships in global environmental policy: The Clean Development Mechanism. The Journal of Environmental Development, 13(1), 295-322.

United Nations Global Compact. (2014). Global compact governance. www.unglobalcompact.org. Accessed April 30, 2014. 